\title{
Ceftriaxone versus ampicillin/ cloxacillin as antibiotic prophylaxis in elective caesarean section
}

E-T.S. Ahmed, ${ }^{1}$ O.A. Mirghani, ${ }^{1}$ A-S. Gerais ${ }^{2}$ and I. Adam ${ }^{3}$

$$
\begin{aligned}
& \text { السيفتياكسون مقابل الأمبيسيلين والكلوكساسيلين كمضادات حيوية وقائية في العملية القيصرية } \\
& \text { الانتقائية } \\
& \text { التيجاني صديق أحمد، عمر أحمد ميرغني، سلام جريس، إسحق آدم }
\end{aligned}
$$

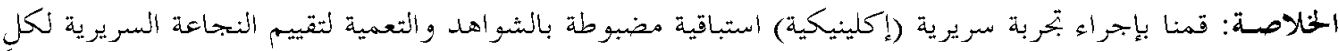

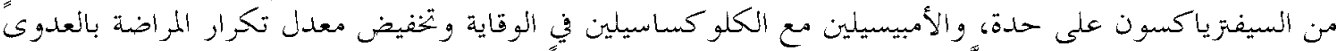

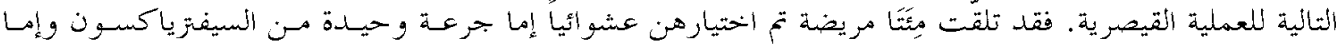

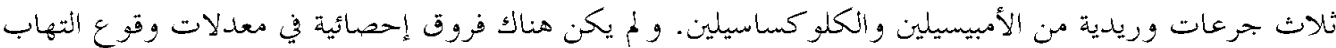

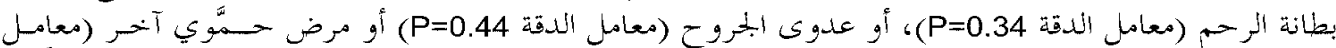

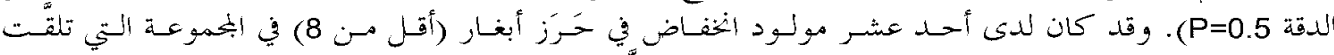

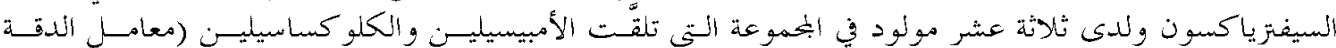

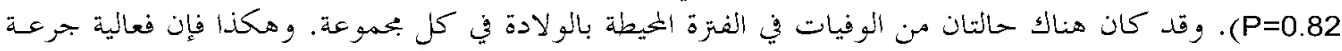

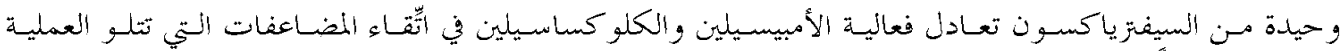

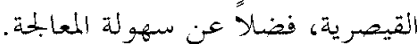

ABSTRACT We carried out a prospective, randomized, controlled clinical trial to evaluate the clinical efficacy of ceftriaxone and ampicillin/cloxacillin prophylaxis in decreasing the frequency of post-caesarean section infection-related morbidity. Two hundred patients randomly received either ceftriaxone (single dose) or ampicillin/cloxacillin (3 doses) intravenously at induction of anaesthesia. There was no statistical difference in incidence of endometritis $(P=0.34)$, wound infection $(P=0.44)$, or other febrile morbidity $(P=0.5)$. Eleven babies had a low Apgar score $(<8)$ in the ceftriaxone group and 13 in the ampicillin/cloxacillin group $(P=$ 0.82 ). There were 2 perinatal deaths in each group. One dose of ceftriaxone was as effective as ampicillin/ cloxacillin in preventing post-caesarean section complications and is easier to administer.

\begin{abstract}
Antibioprophylaxie pour une césarienne élective : comparaison entre la ceftriaxone et l'ampicilline-cloxacilline

RESUME Nous avons réalisé un essai clinique contrôlé, randomisé et prospectif afin d'évaluer l'efficacité clinique de la prophylaxie par ceftriaxone et ampicilline-cloxacilline dans la réduction de la fréquence de la morbidité liée à l'infection après une césarienne. Deux cent patientes ont reçu de manière aléatoire soit de la ceftriaxone (dose unique) soit de l'ampicilline-cloxacilline (3 doses) par voie intraveineuse à l'induction de l'anesthésie. II n'y avait pas de différence statistique dans l'incidence de l'endométrite $(p=0,34)$, l'infection de la plaie $(p=0,44)$, ou toute autre morbidité fébrile $(p=0,5)$. Onze bébés avaient un score d'Apgar faible $(<8)$ dans le groupe de la ceftriaxone et 13 dans le groupe de l'ampicilline-cloxacilline $(p=0,82)$. II y a eu deux décès périnatals dans chaque groupe. Une dose de ceftriaxone était aussi efficace que l'ampicillinecloxacilline dans la prévention des complications de la césarienne et elle est plus facile à administrer.
\end{abstract}

${ }^{1}$ University of Gezira, Wad Medani, Sudan.

'University of Khartoum, Khartoum, Sudan.

${ }^{3}$ New Halfa Hospital, New Halfa, Sudan.

Received: 09/10/02; accepted: 14/09/03

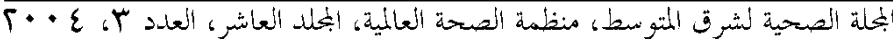




\section{Introduction}

Caesarean section is an essential operation and is practised widely. Over the past 3 decades, the rate of caesarean section has increased steadily, and may reach up to $25 \%$ in some centres [1]. Maternal morbidity related to infection after caesarean section has been reported to be 8 -fold higher than after vaginal delivery, and endometritis is the most common major complication occurring after caesarean section, with an incidence of $5 \%-40 \%$ [2]. A reduction in cases of endometritis by two-thirds to three-quarters justifies the administration of prophylactic antibiotics to women undergoing caesarean section $[3,4]$. Controversy still exists about which antibiotic should be used for prophylaxis, and the best prophylactic regimen has yet to be described; cephalosporins have frequently been used [5]. The newer antimicrobials must be compared against the old standard (ampicillin) and their clinical applicability determined.

The purpose of this study is to compare the efficacy of ceftriaxone with ampicillin/ cloxacillin in preventing post-operative complications (endometritis, wound infec- tion and other febrile morbidity) in women undergoing delivery by elective caesarean section.

\section{Methods}

This study was carried out during the period January-June 2001 at Wad Medani Teaching Hospital (central Sudan). Two hundred patients who planned elective caesarean section for various reasons (e.g. cephalopelvic disproportion, repeated scars) were enrolled in the study in 2 groups, 100 patients in each group. There were no statistical differences in the admission variables between the 2 groups, (Table 1 ). Women were excluded from the study if they had received antibiotics within 2 weeks prior to the operation; if they had any visible infection at any site or elevated temperature at the time of the operation; if they were allergic to any of the antimicrobials used; or if they did not wish to participate in the study.

Patients were randomized to receive either ceftriaxone as single dose of $1 \mathrm{~g}$ or $1 \mathrm{~g}$ ampicillin/cloxacillin every 8 hours. Both drugs were given intravenously at induc-

\begin{tabular}{|c|c|c|c|}
\hline Variable & Ceftriaxone & $\begin{array}{l}\text { Ampicillin/ } \\
\text { cloxacillin }\end{array}$ & P-value \\
\hline Temperature $\left({ }^{\circ} \mathrm{C}\right)$ & $37.05(0.22)$ & $37.07(0.25)$ & 0.55 \\
\hline Weight (pounds) & $156.33(29.36)$ & $154.65(29.22)$ & 0.68 \\
\hline $\begin{array}{l}\text { Gestational age } \\
\quad \text { (weeks) }\end{array}$ & $38.62(1.57)$ & $38.67(1.30)$ & 0.81 \\
\hline $\begin{array}{l}\text { Pre-operative } \\
\text { haemoglobin (g/L) }\end{array}$ & $9.58(0.86)$ & $9.60(1.08)$ & 0.11 \\
\hline
\end{tabular}

Values given are means (standard deviations).

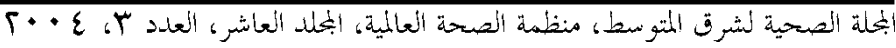


tion of anaesthesia. After giving verbal consent, a complete history of the participants was taken using a standard questionnaire. A physical examination was also performed. The outcomes examined were the incidence of:

- post-operative febrile morbidity, defined as an oral temperature of $\geq 38.0^{\circ} \mathrm{C}$ on 2 occasions at least 4 hours apart, excluding the first 24 hours;

- post-operative infection, which includes:

- endometritis (fever, uterine tenderness and abnormal lochia)

- wound infection (fever, cellulitis and exudates)

- pelvic abscess (collection of pus)

- peritonitis (elevated temperature, tachycardia, abdominal distension and pain with guarding and rigidity aggravated by moving and breathing with absent bowel sounds at the onset of paralytic ileus)

- other febrile morbidity, e.g. urinary tract infection, chest infection, malaria $[6,7]$.

Once febrile morbidity was identified, patients were examined to localize the potential source of infection (tonsils, breasts, chest, abdomen and pelvis). Urine analysis (followed by urine culture and sensitivity testing if the result of examination was suggestive of infection); total white blood cell count. Blood and cervical swabs were sent for culture (MacConkey agar) and sensitivity testing. Blood films (thin and thick) were taken by finger pricks and Giemsa stained to confirm or to exclude malaria.

The policy in Wad Medani Hospital is to treat post-caesarean section febrile morbidity (endometritis, peritonitis and pelvic abscess) with triple antibiotic treatment (ampicillin/cloxacillin $500 \mathrm{mg} 6$ hourly, gentamicin $80 \mathrm{mg} 8$ hourly, metronidazole $500 \mathrm{mg} 8$ hourly for 7 days). If there is no response, these drugs are changed to antibiotics in accordance with the result of the culture sensitivity test.

Data were analysed using SPSS. The chi-squared test, Student $t$-test and Fischer exact test were used where applicable. A $P$ value of $<0.05$ was considered significant.

\section{Results}

During the period of this study (JanuaryJune 2001) there were 2364 vaginal deliveries and 550 caesarean sections (18.8\%), $307(55.8 \%)$ of them elective and 243 $(44.2 \%)$ emergency caesarean sections. There were 5 cases of maternal death from septicaemia following emergency caesarean section.

The operations were performed by consultant, $23 \%$, registrar, $67 \%$ and house officer, $10 \%$ in the ceftriaxone group, while in the ampicillin/cloxacillin group, $21 \%$ were done by consultant, $70 \%$ by registrar and $9 \%$ by house officer.

No statistically significant difference was found in post-operative febrile morbidity between the 2 groups ( $7 \%$ ceftriaxone $6 \%$ ampicillin/cloxacillin, $P=0.64)$. There were 2 cases of endometritis $(2 \%)$ in the ceftriaxone group and 1 in the ampicillin/ cloxacillin group, with no statistically significant difference $(P=0.34)$.

There was 1 case of wound infection in the ceftriaxone group and 2 in the ampicillin/cloxacillin group, with no statistical difference $(P=0.44)$. These wound infections were superficial and only 1 was associated with febrile morbidity. They did not require local drainage but were dressed twice daily. Staphylococcus aureus, sensitive to gentamicin, was isolated and the patient responded satisfactorily to treatment.

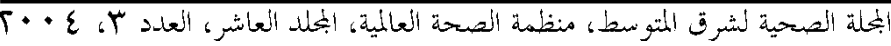


The incidence of peritonitis was $1 \%$ in each group $(P=0.39)$. There were 5 cases of other febrile morbidity not associated with endometritis (4 malaria, 1 chest infection). Three of the other febrile morbidity cases were in the ceftriaxone group, while 2 were in the ampicillin/cloxacillin group $(P$ $=0.5)$ (Table 2).

There were 11 babies with low Apgar score $(<8)$ at 1 and 5 minutes in the ceftriaxone group and 13 in the ampicillin/cloxacillin group $(P=0.82)$. There were 4 perinatal deaths, 2 in each group, with no statistically significant difference (Table 2). One of the babies died due to respiratory distress syndrome associated with maternal diabetes mellitus, the second had congenital heart disease; the other 2 were unexplained deaths.

Three patients suffered vomiting and 1 patient in the ceftriaxone group developed a maculopapular skin rash; this occurred immediately after drug administration and resolved spontaneously without treatment. No patient suffered adverse drug effects in

\begin{tabular}{|c|c|c|c|}
\hline Variable & $\begin{array}{c}\text { Ceftriaxone, } \\
\%\end{array}$ & $\begin{array}{l}\text { Ampicillin/ } \\
\text { cloxacillin, \% }\end{array}$ & $\begin{array}{c}P \text { - } \\
\text { value }\end{array}$ \\
\hline $\begin{array}{l}\text { Febrile } \\
\text { morbidity }\end{array}$ & 7 & 6 & 0.64 \\
\hline Endometritis & 2 & 1 & 0.34 \\
\hline $\begin{array}{l}\text { Wound } \\
\text { infection }\end{array}$ & 1 & 2 & 0.44 \\
\hline Peritonitis & 1 & 1 & 0.39 \\
\hline $\begin{array}{l}\text { Other febrile } \\
\text { illness }\end{array}$ & 3 & 2 & 0.50 \\
\hline Apgar score $<8$ & 11 & 13 & 0.82 \\
\hline Perinatal death & 2 & 2 & 0.50 \\
\hline
\end{tabular}

the ampicillin/cloxacillin group. There was no statistically significant difference between groups.

\section{Discussion}

This study was carried out to test the efficacy of prophylactic antibiotic ceftriaxone in reducing post-caesarean section morbidity in elective caesarean section. Most other studies have examined the use of prophylactic antibiotics in unscheduled (emergency) caesarean section, which carry the most important potential risk factors for sepsis [8].

The policy of using prophylactic antibiotics in elective caesarean section was justified by the high rate in our community of post-caesarean section morbidity, namely sepsis, with eventual maternal mortality, as evidenced by the 5 maternal deaths complicating emergency caesarean section during the period of the study. Moreover, septicaemia is one of the main causes of maternal mortality in central Sudan, and is the leading cause of maternal death in Wad Medani Hospital $[9,10]$.

The incidence of post-operative febrile morbidity was $6 \%-7 \%$, with no significant statistical difference between the 2 groups. This figure is near to the incidence (3.3\%) of post-operative febrile morbidity found when cefazolin (versus placebo) was used for elective caesarean section in Saudi Arabia [5]. The incidence of post-operative febrile morbidity in our study may be influenced by a unique factor (malaria). Recently it has been reported that susceptibility to malaria may extend even to the postpartum period and this may be due to the extension of alteration in cellular immunity [11]

It is not surprising that both regimens of antibiotics (ampicillin/cloxacillin and ceftriaxone) failed to eliminate post-caesarean

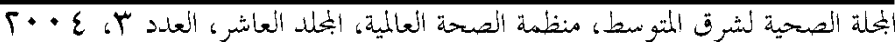


morbidity completely, and 3 cases of endometritis $(1.5 \%)$ and 3 cases of wound infection $(1.5 \%)$ occurred (treated effectively). These findings resemble other investigations which demonstrated that prophylactic antibiotics were effective in reducing (not eliminating) approximately $50 \%$ of post-caesarean section infections [12].

Despite comparing a single dose of ceftriaxone with multiple doses of ampicillin/cloxacillin, there was no statistical difference in the incidence of postcaesarean febrile morbidity; this is on a par with the results of a previous study on post- caesarean morbidity comparing a single dose of ceftriaxone and multiple doses of cefoxitin [13]. Nevertheless, ceftriaxone has been shown to reduce post-caesarean section febrile morbidity in comparison to other antibiotics or placebo [14].

In our study, we compared ceftriaxone with our standard drug treatment, ampicillin/cloxacillin, which is one of the components (ampicillin/cloxacillin, gentamicin, metronidazole) in treating endometritis in our hospital. In spite of this, cases of endometritis and wound infection were treated effectively. Some investigators contend that drugs used as a first line therapeutic agent should not be used as prophylactic agent to avoid emergence of resistant strains [15]. There is no evidence that ampicillin/cloxacillin prophylaxis interferes with its use post-operatively, but the possible emergence of resistant organisms is a valid concern.

Although the prices of these 2 drugs do not differ much, the single dose of ceftriaxone is certainly easier to administer than the 3 doses of ampicillin/cloxacillin and can save a great deal of nursing time.

\section{Acknowledgements}

We wish to thank all the patients and their families for their excellent cooperation, and also the nursing and technical staff at Wad Medani Teaching Hospital. We are very grateful to the local health authorities in Gezira state. The drugs were donated by Alhikma Company, Wad Medani, Sudan.

\section{References}

1. Placek PJ, Taffel SM. Recent pattern of cesarean delivery in the United States. Obstetrics and gynecology clinics of North America, 1988, 15:607-27.

2. Nielson TF, Hokegard KH. Postoperative cesarean section morbidity: A prospective study. American journal of obstetrics and gynecology, 1983, 146:911-6.

3. Smaill F, Hofmeyr GJ. Antibiotic prophylaxis for caesarean section (Cochrane review). Chichester, John Wiley \& Sons (Cochrane library, Issue 2), 2000.

4. Smaill F. Antibiotic prophylaxis and caesarean section. British journal of obstetrics and gynaecology, 1992, 99:789-90.
5. Rouzi AA et al. The routine use of cefazolin in cesarean section. International journal of gynecology and obstetrics, 2000, 69:107-12.

6. Cunningham FG et al., eds. Williams obstetrics, 19th ed. Norwalk, Connecticut, Appleton \& Lange, 1993:627-42.

7. Horan TC et al. CDC definition of nosocomial surgical site infections, 1992: a modification of CDC definitions of surgical wound infections. Infection control and hospital epidemiology, 1992, 13: 606-8.

8. Pedersen TK, Blaakaer J. Antibiotic prophylaxis in cesarean section. Acta obs-

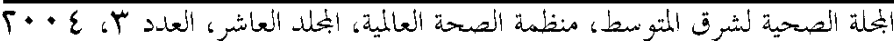


tetricia et gynecologica scandinavica, 1996, 75:537-9.

9. Mirghani AO, Magzoub MM. A community-based survey on the incidence and etiology of maternal mortality in Gezira province, Sudan. Saudi medical journal, 1992, 13:249-53.

10. Dafallah $S$ et al. Maternal mortality in a teaching hospital in Sudan. Saudi medical journal, 2003, 24:369-73.

11. Diagne $\mathrm{N}$ et al. Increased susceptibility to malaria during early postpartum period. New England journal of medicine, 2000, 343:598-603.

12. Polk BF. Antimicrobial prophylaxis to prevent mixed bacterial infection. Journal of antimicrobial chemotherapy, 1981, 8: 115-29.

13. Von Mandach $U$ et al. Ceftriaxone (single dose) versus cefoxitin (multiple doses): success and failure of antibiotic prophylaxis in 1052 cesarean sections. Journal of perinatal medicine, 1993, 21:385-97.

14. Sulvoic $V$ et al. Ceftriaxone in prevention of complications after cesarean section and its influence on the newborn. Clinical and experimental obstetrics \& gynecology, 1994, 21:33-7.

15. Mirghani OA. Post-caesarean section infection. Gezira journal of health sciences, 2003, 1:84-107.

\section{Beyond the numbers: Reviewing maternal deaths and complica- tions to make pregnancy safer}

Every year some 8 million women suffer pregnancy-related complications and over half a million die. Most of these deaths can be averted even where resources are limited but, in order to do so, the right kind of information is needed upon which to base actions. Knowing the statistics on levels of maternal mortality is not enough - information that helps us identify what can be done to prevent such unnecessary deaths is needed. Beyond the numbers presents ways of generating this kind of information. The approaches described go beyond just counting deaths to developing an understanding of why they happened and how they can be averted. It is directed at health professionals, health care planners and managers working in the area of maternal and newborn health who are striving to improve the quality of care provided. The publication includes a CD-ROM of sample data collection and analysis forms to serve as a basis for local adaptation.

The document can be obtained from Marketing and Dissemination, World Health Organization, 20 Avenue Appia, 1211 Geneva 27, Switzerland (telephone: +41 22791 2476; fax: +41 22791 4857; email: bookorders@who.int).

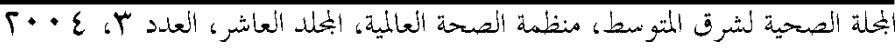

